\title{
Wave Cycle Design for Wave Rotor Gas Turbine Engines With Low NO Emissions
}

CFD Research Corporation, Huntsville, AL 35805

\author{
E. L. Resler, Jr. \\ Sibley School of Mechanical \\ and Aerospace Engineering. \\ Cornell University. \\ Ithaca, NY 14853
}

The wave rotor is a promising means of pressure-gain for gas turbine engines. This paper examines novel wave rotor topping cycles that incorporate low-NO $\mathrm{O}_{x}$ combustion strategies. This approach combines two-stage "rich-quench-lean" ( $R Q L)$ combustion with intermediate expansion in the wave rotor to extract energy and reduce the peak stoichiometric temperature substantially. The thermodynamic cycle is a type of reheat cycle, with the rich-zone air undergoing a high-pressure stage. Rich-stage combustion could occur external to or within the wave rotor. An approximate analytical design method and CFD/combustion codes are used to develop and simulate wave rotor flow cycles. Engine cycles designed with a bypass turbine and external combustion demonstrate a performance enhancement equivalent to a 200-400 $R$ $(110-220 \mathrm{~K})$ increase in turbine inlet temperature. The stoichiometric combustion temperature is reduced by $300-450 R(170-250 \mathrm{~K})$ relative to an equivalent simple cycle, implying substantially reduced $N O_{x}$ formation.

\section{Introduction}

The development of more efficient, less polluting gas turbines requires the pressure ratios and temperatures of conventional components to be pushed to unproved limits, while curbing the formation of oxides of nitrogen $\left(\mathrm{NO}_{\mathrm{x}}\right)$ at high tem peratures. The wave rotor is a single component combining gas compression, expansion, and possibly combustion, with the potential for significantly increasing specific power and decreasing fuel consumption in advanced turbine engines.

A wave rotor utilizes direct fluid-fluid energy exchange in channels using pressure waves, as in a shock tube. A number of channels separated by thin walls are arrayed on the periphery of a cylindrical rotor. The wave processes are made periodic by turning the rotor to connect the channels intermittently with appropriately located inlet and outlet manifolds. The closing and opening of the ends of each channel, by the use of stator end plates between the manifolds, initiates compression or expansion waves in the channel, similar to the breaking of a shock tube diaphragm. The simplest wave rotors have straight constant-area axial channels and are turned by an external drive. Free-running wave rotors and wave turbines may have slanted or curved channels for self-rotation and shaft work output. A "wave rotor combustor" is a wave rotor in which combustion occurs on-board, within its channels.

An important feature of wave rotors is that when the channel walls are alternately exposed to hot and cold fluid, their temperature can be maintained below the peak temperature in the fluid. In a gas turbine engine this feature permits using a cycle that circumvents the usual turbine inlet temperature (TIT) limitation. Considerable historical information and reviews of progress in wave rotors can be found in the proceedings of the 1985 Naval Postgraduate School Wave Rotor Workshop (Shreeve and Mathur, editors) and the works of Sladky (1984), Azoury (1965-66), and Foa (1960). Currently, a research program at the NASA Lewis Research Center is pursuing basic studies of wave rotor performance and loss mechanisms (Wilson, 1993),

\footnotetext{
${ }^{1}$ Present address: NASA Lewis Research Center, Cleveland, OH 44135.

Contributed by the International Gas Turbine Division and presented at the 40th International Gas Turbine and Aeroengine Congress and Exhibition, Houston. Texas, June 5-8, 1995. Manuscript received by the International Gas Turbine Institute March 2, 1995. Paper No. 95-GT-245. Associate Technical Editor: C. J. Russo.
}

to obtain reliable models that will be useful in future aircraft propulsion designs. Recent work at Cornell University focused on analytic methods (Resler et al. 1994) and $\mathrm{NO}_{\mathrm{x}}$ control (Nalim et al., 1993; Nalim, 1994a).

Topping Cycle With External ${ }^{2}$ Combustion. The most straightforward application of a wave rotor in a gas turbine is to provide a topping cycle to increase the efficiency and overall cycle work. Low-pressure air is compressed in the wave rotor passages by compression waves generated by hot combustion gases from an external steady flow combustor. The hot gases expand and cool before being sent to the turbine, which therefore operates at a lower temperature than the combustor exit.

The application of a wave rotor in a topping cycle has several advantages over turbomachinery technology:

(a) Flow passages are self-cooled since they are alternately exposed to cool compressor discharge air and hot combustor exit flow. Thus, it is able to provide higher peak cycle temperatures without the need for correspondingly advanced materials.

(b) The rotational speed can be kept relatively low, resulting in greater durability and/or higher peak cycle temperatures.

(c) It can provide efficient compression at the high-pressure end of the cycle where conventional compressors suffer from severe tip leakage due to the small flow passage.

(d) It provides a rapid response to transient operating conditions.

$\mathrm{NO}_{\mathbf{x}}$ Emissions. Improvement of gas turbine performance requires a higher peak cycle temperature, but this may increase $\mathrm{NO}_{\mathrm{x}}$ emissions. Near-stoichiometric mixtures produce the most $\mathrm{NO}$, the major component of engine $\mathrm{NO}_{\mathrm{x}}$. Here, NO formation estimates are presented as grams of equivalent $\mathrm{NO}_{2}$ per $\mathrm{kg}$ fuel, called the $\mathrm{NO}_{\mathrm{x}}$ emissions index $\left(\mathrm{EINO}_{\mathrm{x}}\right)$.

One $\mathrm{NO}_{\mathrm{x}}$-reducing combustor scheme being considered for advanced aircraft and other applications is the Rich-QuenchLean (RQL) concept. The two-stage RQL scheme employs fuel-rich combustion in the first stage, where $\mathrm{NO}_{\mathrm{x}}$ formation is low because of low oxygen availability, despite fast kinetics.

\footnotetext{
${ }^{2}$ External to the rotor, but still internal in the thermodynamic sense of combustion in the working fluid.
} 


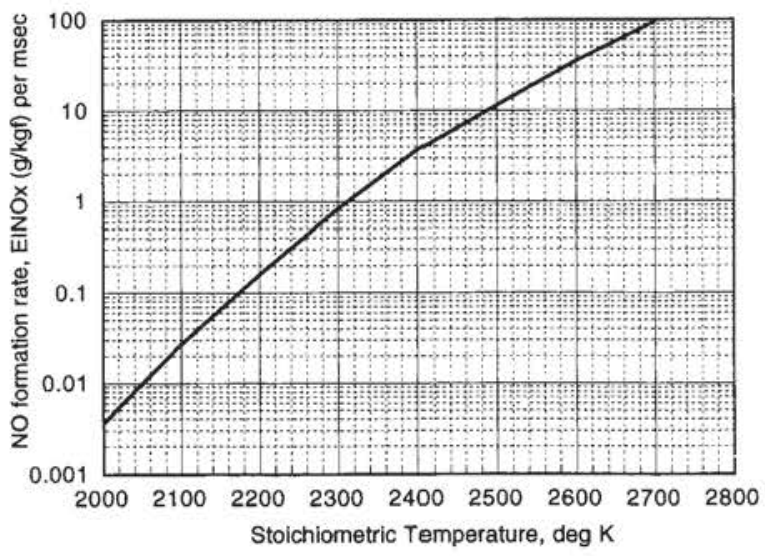

Fig. 1 NO formation at stoichiometric conditions

Additional air is then injected into the rich-burn products with very rapid mixing to a sufficiently low temperature to minimize $\mathrm{NO}_{\mathrm{x}}$ formation, and combustion is completed in the now lean mixture.

There are two major challenges encountered with this scheme. First, the rich zone is very hot $(2200-2500 \mathrm{~K})$, but the combustor wall cannot be cooled by a film of air as in ordinary combustors since excessive $\mathrm{NO}_{\mathrm{x}}$ will be formed. Second, the large volume of air that bypassed the rich-burn section must quickly mix with the rich burn products without forming excessive $\mathrm{NO}_{\mathrm{x}}$. The peak temperature in the mixing zone and the pressure drop available for injection of air are critical factors controlling mixing-zone $\mathrm{NO}_{\mathrm{x}}$ formation. The use of a wave rotor allows both these critical parameters to be addressed. Most $\mathrm{NO}_{\mathrm{x}}$ in RQL combustors is produced in the mixing zone, where a diffusion-type flame exists with near-stoichiometric conditions. The mixing rate (and $\mathrm{NO}_{\mathrm{x}}$ ) depends on the momentum flux ratio of the two streams at injection. A pressure difference of about 8-10 percent is desirable for mixing, but this results in a significant efficiency penalty for conventional engines. Figure 1 is a graph of the NO formation rate in a stoichiometric mixture, based on Zeldovich kinetics. It illustrates the strong temperature dependence of the NO formation rate, and thus the importance of limiting the stoichiometric temperature.

\section{Wave Rotor Engine Concepts With Low $\mathrm{NO}_{\mathrm{x}}$ Potential}

Although the wave rotor permits a higher combustor exit temperature relative to the TIT, $\mathrm{NO}_{\mathrm{x}}$ limitations may still constrain combustor temperatures. We seek to design a wave rotor flow cycle and a corresponding engine cycle to mitigate or circumvent this constraint, and even to enhance the effectiveness of the combustor strategies used to reduce $\mathrm{NO}_{\mathrm{x}}$.

The wave rotor allows two new concepts to control $\mathrm{NO}_{\mathrm{x}}$ while boosting engine performance. One concept is to stage the combustion process in rich and lean sections, similar to the RQL scheme, and to use a wave rotor between the stages to extract energy from the rich product gas. The product gas cools by expansion ("wave quenching" at constant composition) in the wave rotor and thus lowers the stoichiometric temperature in the mixing zene of the second stage where most $\mathrm{NO}_{\mathrm{x}}$ is otherwise produced in RQL-type combustors. Also, part of the energy extracted is available via the wave rotor to boost the pressure of the bypass air injected in the second stage. The pressure differential for mixing can be increased to about 10 percent without a significant penalty, for enhanced mixing and minimal residence time at stoichiometric conditions. We refer to this concept as Rich-Wave-Quench-Lean (RWQL).

The other concept is to accomplish combustion within the wave rotor channels, followed by immediate wave expansion of the hot gas, so that the residence time at peak temperature is minimal. The near-constant-volume combustion produces a pressure gain. In general, this may be done with lean or rich combustion. For combination with the RWQL concept, the wave rotor provides the rich combustion stage. Its additional advantages are that: (a) the need for a high temperature liner for the rich combustion zone is eliminated, (b) residence time at peak temperature could be reduced to a fraction of a millisecond, and (c) mechanical complexity is reduced; the ducting is much simplified and fewer special-shape manifolds are needed. In-rotor combustion is less well understood and more challenging than steady-flow combustors, and has not been convincingly demonstrated in practice. Well-controlled intermittent combustion with sufficient rapidity and reliability would have to be achieved. With rich combustion, mixing with air at high temperature must be controlled. Therefore, the emphasis in this paper will be on the RWQL concept with external, rather than with in-rotor combustion.

The RWQL thermodynamic cycle is similar to a reheat cycle, with a part of the air participating in the high-pressure richburn stage. The cycle work and efficiency of the cycle is thus considerably enhanced beyond conventional Brayton cycle performance for the same TIT, while mixing-zone $\mathrm{NO}_{\mathrm{x}}$ formation is greatly reduced. The reduction in stoichiometric temperature is equivalent to a reduction in inlet temperature for a unitary combustor. $\mathrm{NO}_{\mathrm{x}}$ emissions are expected to be considerably less than with RQL or lean-premixed-pre-vaporized (LPP) combustion in simple cycles.

Splitter RWQL Scheme. The simplest version of the RWQL approach is the "Splitter" RWQL scheme, in which the air being compressed within the wave rotor is split in two streams: (1) a medium-pressure stream for injection into the quick-mix zone, and (2) a high-pressure stream for the rich stage. This is schematically illustrated in Fig. 2, with alternate flow paths for rich stage combustion external to the rotor or within the rotor (heavy broken line).

Wave Turbine and Bypass Turbine RWQL Schemes. The extent of expansion of the rich product gas is determined by the work transfer effected in the wave rotor. In the ordinary splitter scheme (with external or internal combustion, and axial blades), this is limited to the compression work for the medium and high-pressure streams. However, if the wave rotor is designed with slanted or curved channels so that shaft work is produced in addition to the compression work (making it a wave turbine), the "wave quench" effect can be considerably enhanced.

\section{Nomenclature}

$a=$ speed of sound

$a_{1}=$ reference speed of sound

$\phi=$ fuel/air equivalence ratio

$\gamma=$ specific heat ratio

$\eta=$ cycle efficiency

$\mathrm{K}=$ degrees Kelvin

$\mathrm{L}=$ length of channel

$$
\begin{aligned}
\mathrm{M}= & \text { Mach number } \\
p= & \text { pressure } \\
P= & \text { "rightward moving" characteristic } \\
& \text { quantity, speed }(u+a) \\
Q= & \text { "leftward moving" characteristic } \\
& \text { quantity, speed }(u-a) \\
R= & \text { gas constant } \\
\mathrm{R}= & \text { degrees Rankine }
\end{aligned}
$$

$$
\begin{aligned}
\rho & =\text { density } \\
s & =\text { entropy } \\
t & =\text { time } \\
T & =\text { temperature } \\
u= & \text { fluid velocity } \\
x= & \text { position along channel } \\
y & =\text { fraction of engine flow in a particular } \\
& \text { stream }
\end{aligned}
$$




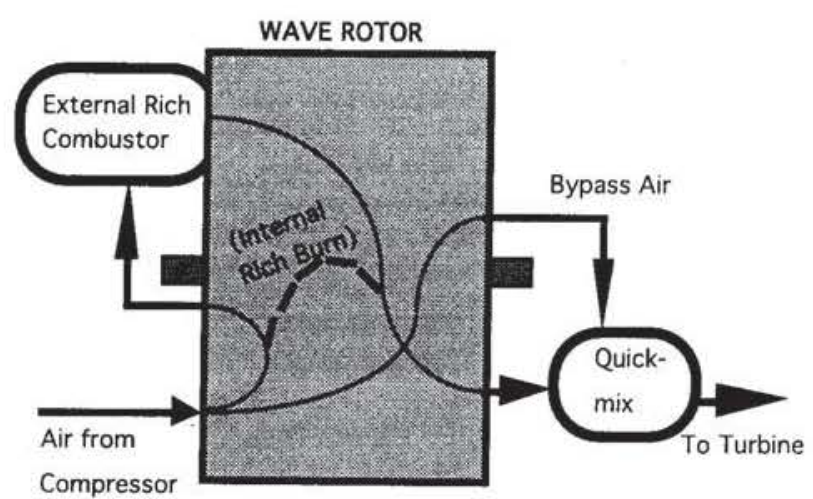

Fig. 2 Splitter RWQL scheme

The practicality of a wave turbine will depend on matching shaft power to drive requirements. An alternative scheme that allows a large wave quench without the complication of a wave turbine is the "Bypass Turbine" RWQL scheme, illustrated in Fig. 3. Bypass air is boosted to the same high pressure as the rich-burn air, thus absorbing a considerable amount of energy from the expanding rich product gas. The excess work must be extracted in a bypass turbine.

The reduction in stoichiometric temperature can be amplified by heat transfer from the rich product gas to the bypass air, via the channel walls and by cooling the rich burner (if external), as well by an optional heat exchanger following the wave rotor. In this way, the bypass air will also contribute to the upper stage of the thermodynamic cycle.

\section{Methods of Analysis}

The following methodology is used to analyze the flow and design the wave rotor:

(a) Initially an approximate nonlinear analytical method is used, which allows a parametric study and gives a design starting point. It uses the theory of characteristics, with some assumptions, and includes losses peculiar to the wave rotor. This method is described in detail by Resler et al. (1994) and Nalim (1994a).

(b) Using boundary condition information from the approximate analysis, a computer code using the method of characteristics generates a wave diagram and provides a preliminary simulation with port timings and fluxes. This code is described by Nalim (1994a).

(c) Detailed CFD calculations are then made using the CFD-FASTRAN finite-volume code. This code solves the time-accurate flow equations. Flux-difference splitting with a min-mod limiter, and explicit Runge-Kutta integration was satisfactory for stable and efficient computation.

(d) For internal combustion simulation, a version of CFDFASTRAN with reactive flow capability is used, and preliminary results have been obtained.

Governing Equations for Analytical and Characteristics Methods. At the simplest level, the wave rotor treated as a "black box" must satisfy the conservation laws. The unsteady flow processes in the wave channels are periodic, and there is no net accumulation of mass or energy in the rotor. Therefore conservation of mass and energy is required of the steady port flows, summed together with any shaft work contribution.

For the internal flow analysis, the length-to-width raitio of the wave-rotor channels is assumed to be sufficiently large for the flow to be treated as one dimensional. Viscous forces and dissipation, heat transfer, and finite-channel-width effects are neglected; however, shock losses are incorporated in the flow solution. Thus, the one-dimensional nonsteady Euler equations apply for the flow in a wave channel.

Using the ideal gas law and the relation $a^{2}=\gamma p / \rho$ for the speed of sound, the conservation equations can be written in terms of $a$ and the entropy, $s$. The hyperbolic character of the equations leads to solutions that can be described in terms of waves. For multi-isentropic flows in constant area straight channels, where individual particles of fluid each have constant (if different) entropy, the equations can be written (see, e.g., Kantrowitz, 1958) as

$$
\frac{\delta^{+}}{\delta t}\left(\frac{2}{\gamma-1} a \pm u\right)=\frac{a}{\gamma R} \frac{\delta^{-} s}{\delta t}
$$

where the directional derivatives are defined by

$$
\frac{\delta^{ \pm}}{\delta t}=\frac{\partial}{\partial t}+(u \pm a) \frac{\partial}{\partial x} .
$$

A third equation is necessary to specify the entropy. For homoentropic flow, the characteristic quantities are constant along the respective characteristic directions (i.e., $P=2 a /(\gamma-1)$ $+u=$ constant along ' $P$ ' or ' + ' characteristics).

Wave Diagrams. The unsteady flow process within the wave rotor is best illustrated by a wave diagram. This may be viewed as an $x$ - $t$ diagram. which is a time history of the flow in any single channel. Alternatively, it may be viewed as an instantaneous "snapshot" of the flow in the entire rotor (ignoring the channel walls), with the rotor "unwrapped" or developed.

Figure 4 is a generic wave diagram for the RWQL schemes with external combustion. The numerals/letters indicate various states or regions of the flow; the ports will be referred to by the adjacent flow region with flow variables identical to those at the port in the channel frame of reference. In the case of the splitter scheme, the shaded port adjacent to state 1 will be open, whereas for the bypass-turbine scheme it will be closed by the end plate.

Figure 5 is a generic wave diagram for a class of schemes with internal combustion; alternate reaction fronts are indicated for shock ignition and spark/heat ignition.

\section{Parametric Study Using Approximate Analytic Method}

A major impediment to the successful design of useful wave rotor cycles has been the lack of complete closed-form analytic solutions for most wave rotor flows with significant work exchange. Given boundary conditions based on preliminary design, numerical codes can be applied. While such codes are necessary for the accurate analysis of a wave cycle design, they

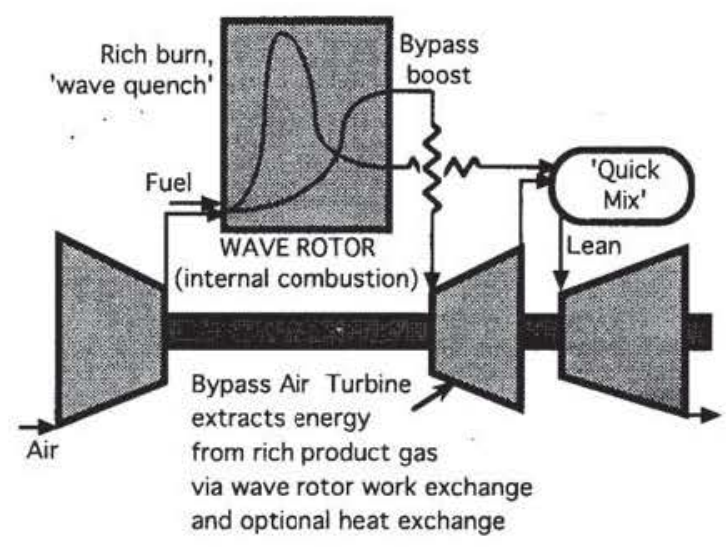

Fig. 3 Bypass turbine RWQL scheme 


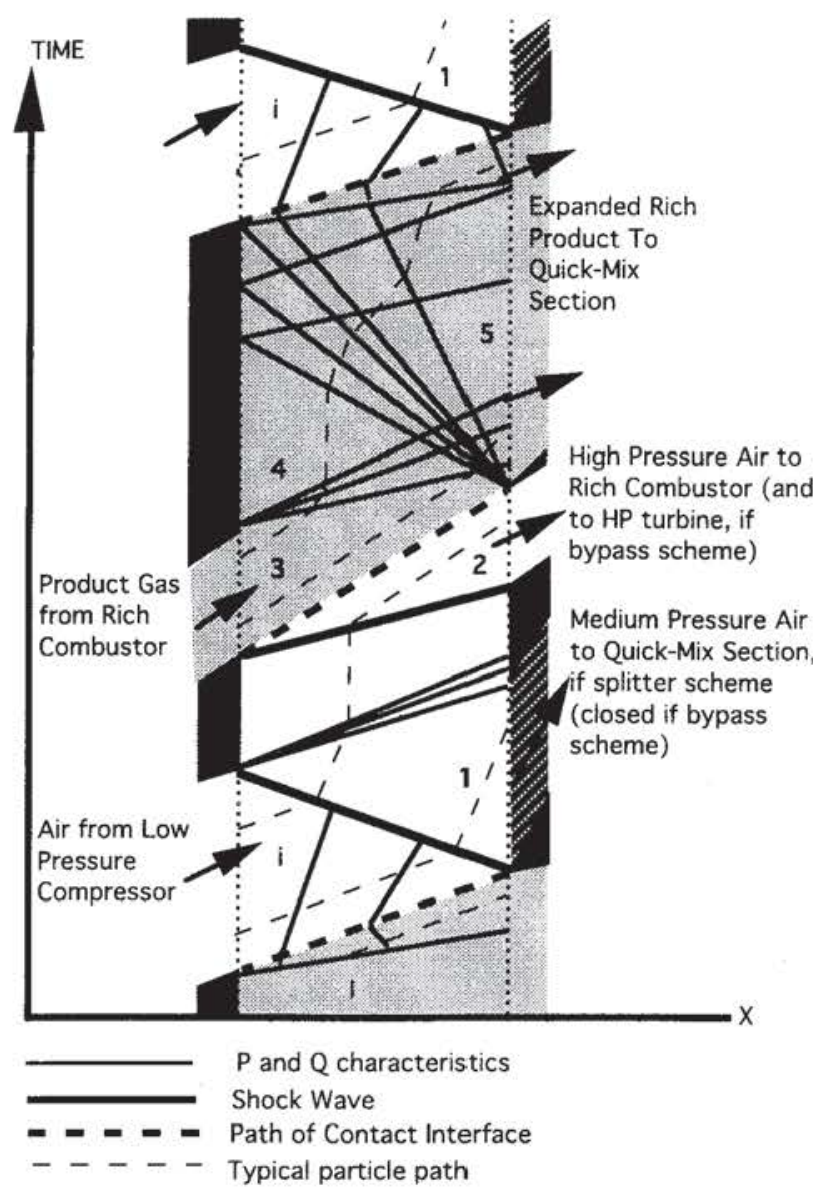

Fig. 4 Wave diagram for RWQL schemes with external combustion

are not by themselves helpful to generate new cycles or to guide a designer quickly to a choice between various wave features.

It is therefore advantageous to develop approximate analytical relations for the nonlinear wave phenomena that occur in wave rotors, making simplifications that lead to useful expressions for preliminary design. The analyses used here are primarily applicable to wave cycles that have uniform flow in a majority of the ports; however, they do yield a complete design of such cycles in an integral sense. The details of any actual nonuniform flow in some ports can then be computed. Using this approach a wave rotor cycle is formulated to perform a desired

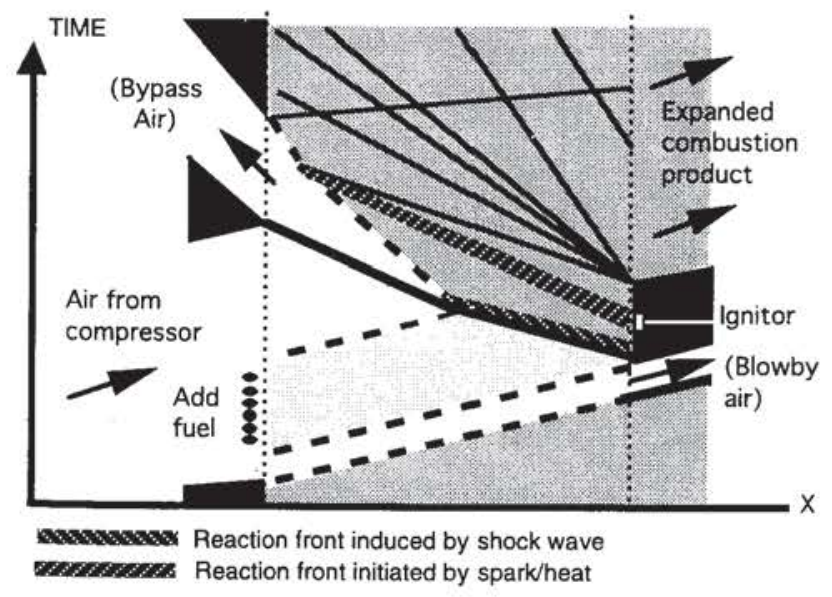

Fig. 5 Wave diagram for internal combustion wave rotor (note Fig. 4 legend)

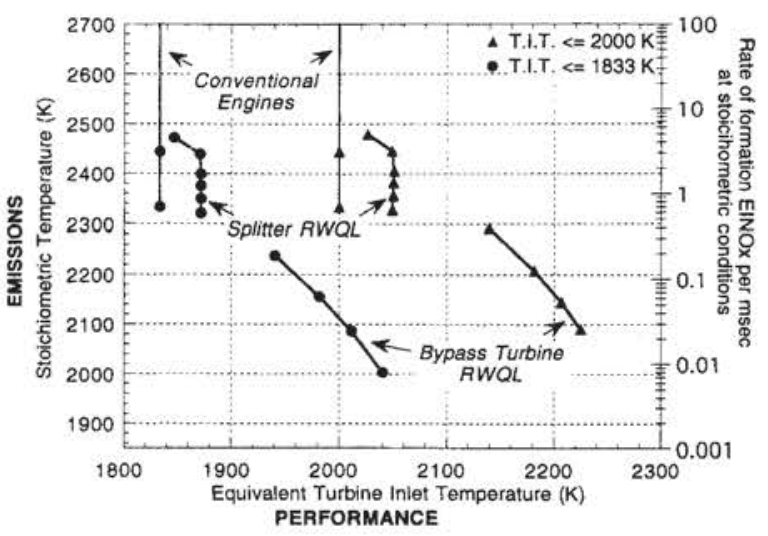

Fig. 6 Performance and emissions reduction potential of RWQL schemes

function as an engine component. The input and output flows of the wave rotor are matched to the constraints imposed by the connecting components, such as a turbine or combustor, and the design performance of the combined system is evaluated. Detailed numerical simulation is then used to refine this model.

The parametric study provides a comparative assessment of the two versions of the RWQL scheme relative to conventional cycle engines. The performance of the RWQL cycle is computed (net cycle work and efficiency) for each combination of parameters, and is then expressed in terms of an equivalent conventional cycle with the same performance. This equivalent cycle is assumed to use perfect loss-free turbomachinery and have a 5 percent combustor pressure drop. The analytic solution is easily set up to optimize the preliminary design with respect to performance and $\mathrm{NO}_{x}$ reduction. This may not necessarily be the optimal solution if detailed flow computation is used. Nevertheless, it is a useful indication of the relative payoff possible with different approaches.

The wave cycle design for the RWQL scheme has a multiplicity of objectives, including bypass air boost pressure and reduction in stoichiometric temperature (whereas four-port topping cycle designs seek only maximum pressure gain). Also, the pressure boost sought for the injection of air in each combustion zone is narrowly specified (around 10 percent pressure drop with some allowance for unaccounted losses). The feasibility of the scheme as judged by these measures and subject to these constraints is sensitive to details of the wave cycle design.

The predicted performance varied with zone stoichiometries and maximum permitted combustion temperature. It was generally found that the performance was better with both rich and lean zone equivalence ratios closer to unity, and with higher rich zone combustion temperature. The results of the analysis are presented in terms of the following variables, which are measures of the performance improvement and $\mathrm{NO}_{\mathrm{x}}$ emissions reduction potential:

1 Stoichiometric temperature in the RWQL cycle, which is a measure of the $\mathrm{NO}_{x}$ formation in the mixing zone.

2 Stoichiometric temperature in the equivalent performance simple cycle (a measure of the avoided $\mathrm{NO}_{\mathrm{x}}$ ).

3 TIT in the RWQL cycle.

4 TIT in the equivalent performance simple cycle, which is a measure of the performance of the RWQL cycle in conventional terms.

Plots of the stoichiometric temperature versus the equivalent TIT are shown in Fig. 6, for two fixed values of the actual TIT limit : $3300 \mathrm{R}(1830 \mathrm{~K})$ and $3600 \mathrm{R}(2000 \mathrm{~K})$. The ambient temperature is fixed at $400 \mathrm{R}(220 \mathrm{~K})$. On the right-hand side, an approximate scale is indicated for the Zeldovich NO formation rate at stoichiometric conditions corresponding to the left- 


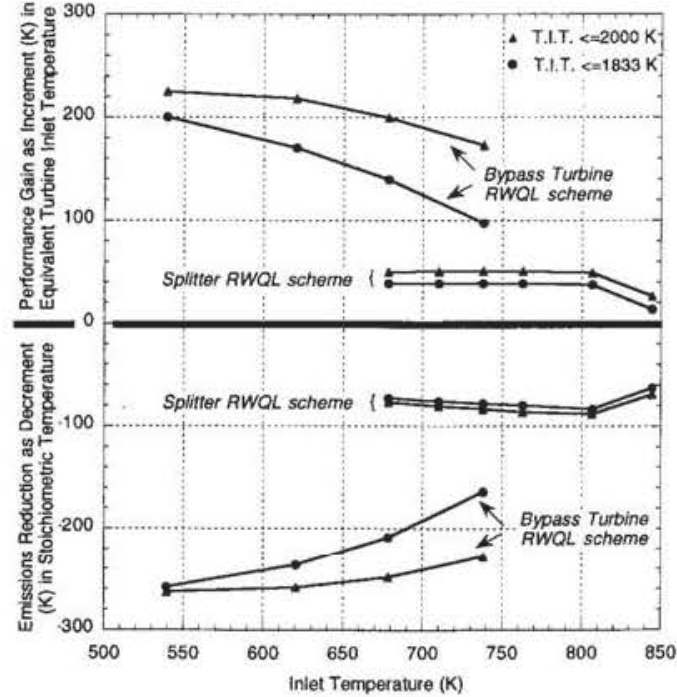

Fig. 7 Increment in equivalent TIT and decrement in stoichiometric temperature

hand side stoichiometric temperature (see Fig. 1). The rich zone equivalence ratio is fixed at 1.8 for the splitter cycle and at 1.5 for the bypass cycle, so that both meet a rich zone temperature limit of $4500 \mathrm{R}(2500 \mathrm{~K})$. The computed results are plotted for a range of inlet conditions to the wave rotor, which satisfies the constraints (as turbocompressor pressure ratio is varied).

Corresponding plots are shown in Fig. 7 of the increment in TIT (equivalent minus actual, upper plot), which is a measure of performance improvement, and the decrement in stoichiometric temperature (actual minus equivalent, lower plot) which is a measure of the reduction in mixing-zone NO formation. Clearly, the bypass turbine scheme is considerably more effective. Note that the results for the bypass turbine do not include the effect of the optional heat exchanger shown in Fig.3 (which would enhance the performance and temperature reduction further)

A sample preliminary design of the bypass turbine scheme (without heat exchange), optimized for temperature limits approximately within those mentioned above, is represented in Fig. 8. This design, involving external rich-stage combustion, was the basis for a detailed flow simulation described below.

The output and thermal efficiency of this engine cycle is calculated to be equivalent to a conventional cycle with a TIT of $3900 \mathrm{R}(2170 \mathrm{~K})$ and a stoichiometric temperature of 4130 $\mathrm{R}(2300 \mathrm{~K})$, whereas the actual TIT is $3500 \mathrm{R}(1940 \mathrm{~K})$ and the mixing zone stoichiometric temperature is $3660 \mathrm{R}(2030$ $\mathrm{K})$. Note that the overall equivalence ratio of 0.85 represents a heat rate about twice that of conventional and advanced low $\mathrm{NO}_{\mathrm{x}}$ engines (without reheat or afterburn).

NO formation is estimated $\left(\mathrm{EINO}_{\mathrm{x}}\right.$ units) as follows:

- Rich zone maximum NO (equilibrium) = 1.6;

- Rich product gas equilibrium NO (after expansion)= 0.001 ;

- $\mathrm{NO}$ formation rate in stoichiometric zone $=0.004$ per ms.

The rich-zone NO is expected to be lower than the theoretical maximum, and the mixing zone contribution is expected to be minimal, as discussed later.

\section{Channel Flow Simulation}

Splitter RWQL Cycle Flow Simulation. The splitter RWQL wave cycle has an inherent limitation similar to that observed in the three-port splitter cycle (e.g., Wilson, 1993), i.e., the outflow/inflow pressure gain for the "throughflow" (bypass exit flow) varies about inversely with the mass fraction exiting in this port (Region 1 in Fig. 4).

In the analytic model of the splitter cycle, there is no "dead time" "between ports $i$ and 3, i.e., 3 opens the instant $i$ is closed. This results in excessive velocity and pressure boost in stream 2 to the rich stage burner. Figure 4 shows a finite dead time, which reduces this loss, because the air in the channel is brought to rest between states 1 and 2 . The bypass port duration, and the exit pressure of the high-pressure stream, is adjustable for maximum benefit. With these features, however, the analytic solution is not applicable. This discussion does not apply to the bypass turbine cycle since port 1 is absent and the channel flow is always brought to rest in region 1 before port 3 is opened.

The bypass air pressure boost is partly determined by the back pressure in port 5 , which must be sufficiently high for the lean combustion stage to be thermodynamically worthwhile. The split air mass ratio and the pressure boost were significantly influenced by the degree of evacuation of the channel when the air inlet port is opened, and by the back pressure at port 5 , when other parameters were held constant.

An effort was made to optimize the air inflow velocity as determined by the timing of the inlet port opening. The analytic model sets the inlet Mach number to 1.0, since this results in a nearly uniform state 1 in the channel, and allows approximate analytic relations between the various thermodynamic states to be established. From the detailed numerical calculations, it was observed that Mach 1 inflow resulted in a more nonuniform hot gas outflow (greater losses). Advancement of the opening time such that the inflow Mach number averaged about 0.6 resulted in better performance.

The trends predicted by the analytic methods (for Mach 1 inflow) are confirmed. The simulations indicate that the stoichiometric temperature in the mixing zone can be reduced by about $100 \mathrm{R}(60 \mathrm{~K})$ compared with an equivalent performance cycle with RQL combustion. Simultaneously, the TIT is reduced by $50 \mathrm{R}(30 \mathrm{~K})$. These benefits are concomitant and cannot be traded against each other, since they both arise from the magnitude of the work transfer that the wave rotor provides from the hot gas to the air.

Bypass Turbine RWQL Cycle Flow Simulation. In the bypass-turbine RWQL scheme (Fig. 3), all the air intended for combustion is pressurized to the maximum pressure of the wave rotor. While a fraction of the air is used for rich combustion at the high pressure, the remainder, preferably after some heat addition, is expanded in a turbine, "in parallel" with the expansion of the rich gas in the wave rotor. The work produced in the turbine represents energy from combustion that is extracted

Bypass mass fraction $=(1-y)=.435$

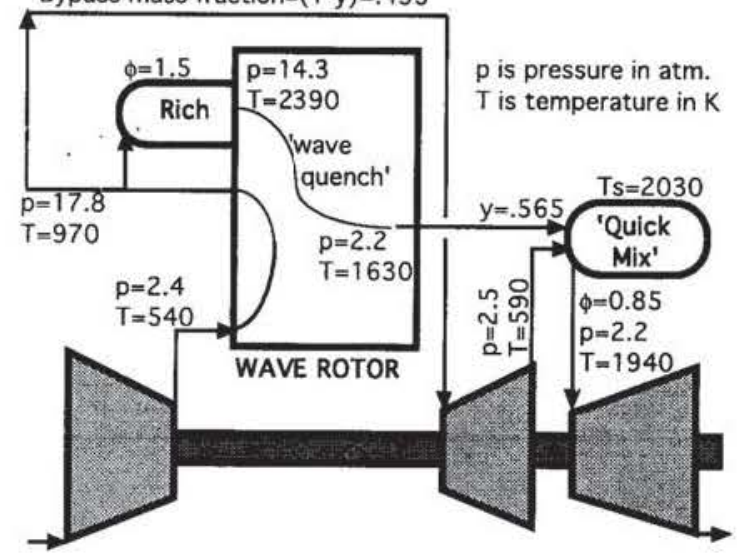

Fig. 8 Sample bypass RWQL cycle 
prior to the combustion gas reaching the stoichiometric state. The two streams are mixed at the exit pressure of the rich gas from the wave rotor. This effectively allows the engine to approach the performance of the ideal stoichiometric engine, while keeping $\mathrm{NO}_{x}$ emissions and the actual turbine temperature within significantly lower limits than expected with an equivalent simple-cycle engine.

CFD simulation of the sample bypass turbine design confirmed the reductions in stoichiometric temperature and in TIT. Figure 9 is a method-of-characteristics solution of a wave cycle for the bypass-turbine RWQL scheme, based on the design of Fig. 8. A distinguishing feature is that no wave compression (which could increase $\mathrm{NO}_{\mathrm{x}}$ formation) is allowed for the hot combustion gas. Figure 10 is a T-S diagram for the engine cycle corresponding to the simulation.

The inviscid flow equations were used in this analysis. Shock losses and losses due to nonuniform flows are accounted, but not viscous and thermal effects. If heat transfer is included or augmented, it is expected that further reduction in stoichiometric temperature will be seen.

\section{Internal Combustion Wave Rotor Analysis}

A preliminary study of combustion in the rotor was undertaken to examine the possible combustion modes and estimate

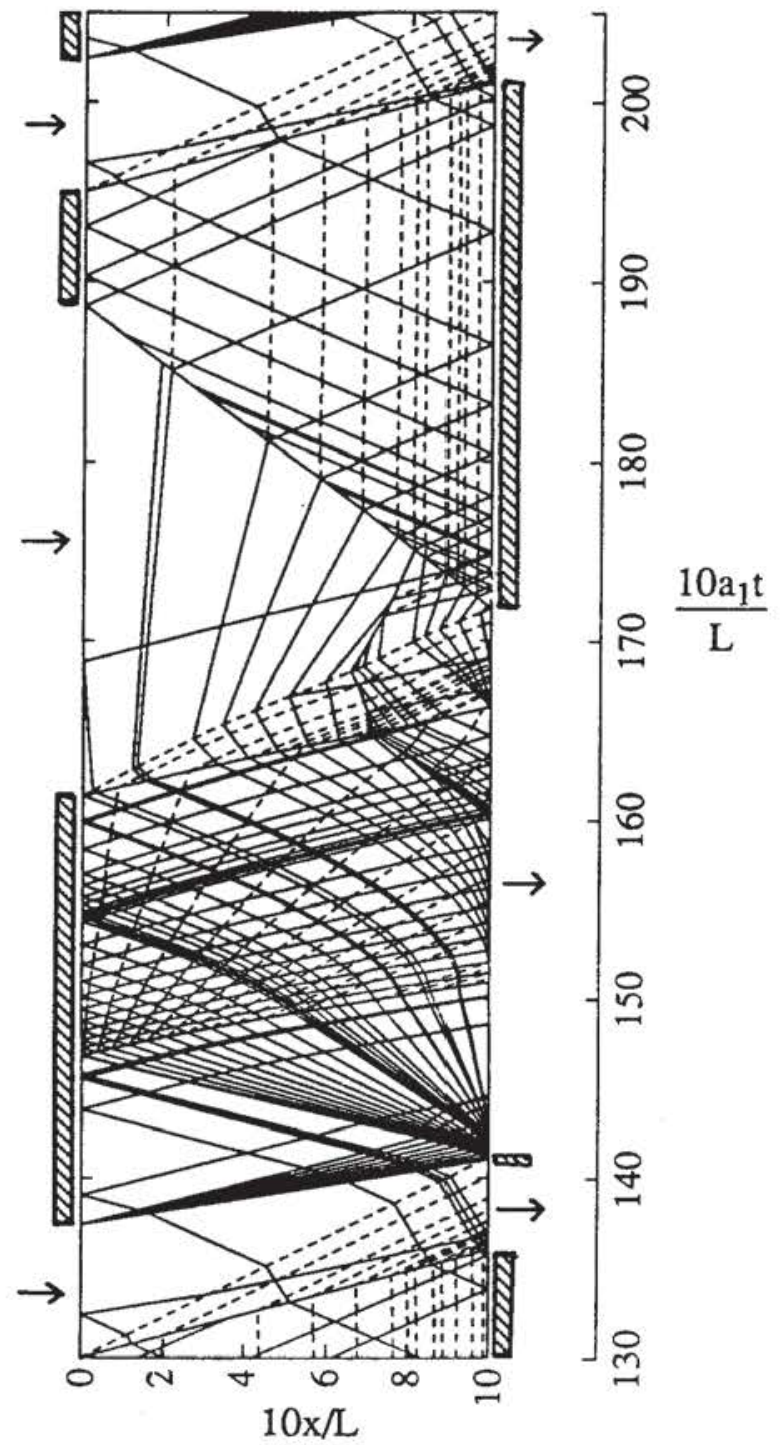

Fig. 9 Method-of-characteristics computed solution of the wave cycle for the sample bypass turbine RWQL scheme

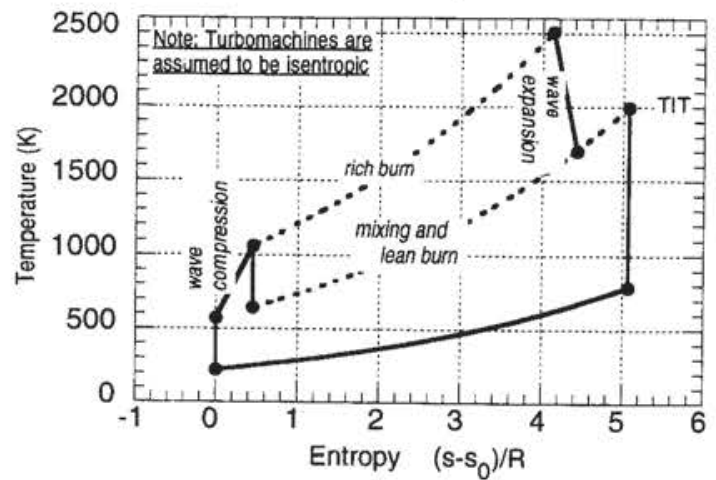

Fig. $10 \mathrm{~T}$-S diagram for sample wave-rotor engine cycle

the burn duration. The numerical analysis was limited to the combustion phase of the wave cycle, ignited by shock heating. The combustion of propane and butane in air was computed, using a simplified (four-step, seven species) global reaction mechanism. Details of results are given by Nalim (1994b).

As expected, the ignitability of a mixture is a strong function of the temperature. Shock ignition was achieved for inflowing stoichiometric mixtures at a temperature above $600 \mathrm{~K}$ and a Mach number of about 0.8 . compressed to rest in the wave rotor by the stopping shock (see Fig. 5). Reaction in the end wall gas (where the shock begins) generates pressure waves, which quickly build up into a detonation front.

For many applications, high inlet temperatures over a range of operating conditions may be unlikely, and the detonation/ shock-ignition mode may be impractical or unreliable. Also, the extremely high transient peak pressure and heat load of a detonation front may be structurally unacceptable. In any case, there is considerable uncertainty about the autoignition kinetics and induction times of many fuels. For better control of the timing and rate of reaction, it may be advisable to limit the initial temperature so compression ignition is not spontaneous and to use a timed ignition source to initiate the reaction front.

Lengthwise flame propagation by laminar deflagration is very slow relative to the time scale of wave motion. Multiple ignition locations along the channel may be used. Once initiated, flame propagation will generate compression heating of the rest of the mixture and may accelerate the reaction front (s). For rapid and reliable combustion with a wide range of inlet conditions, a turbulent flame front similar to that in spark-ignited reciprocating engines is desirable. Turbulence may be generated during inflow, and by injection of a hot gas jet (or two) from a previously fired channel (suggested by early researchers as an ignition method). These design requirements will require further investigation, as part of a complete wave cycle design. A complete design would also require consideration of the methods for restarting the cycle and establishing periodic flow.

For minimum $\mathrm{NO}_{\mathrm{x}}$ formation, the time spent at peak temperature should be kept small. This is possible if an expansion wave is set up to follow the combustion front closely, exhausting the hot gas. The timing of the exhaust port opening has to be adjusted so as not to permit the expansion to quench the combustion front.

\section{NO ${ }_{x}$ Assessment}

There is a trade-off between rich-zone and mixing-zone $\mathrm{NO}_{\mathrm{x}}$ formation, which requires optimization of the system to minimize total $\mathrm{NO}_{\mathrm{x}}$. In conventional RQL systems the mixing zone is responsible for most of the $\mathrm{NO}_{\mathrm{x}}$. In the RWQL schemes, slightly higher rich zone $\mathrm{NO}_{x}$ may be seen, but the mixing zone $\mathrm{NO}_{\mathrm{x}}$ will be drastically reduced.

Because of the thermodynamic advantage of maximizing the heat release at the highest pressure zone, the rich zone may 
operate at a lower equivalence ratio (less rich) than for typical RQL systems. This will also avoid soot formation. When the parameters are optimized for minimum $\mathrm{NO}_{x}$. it is expected that any increase in rich zone $\mathrm{NO}_{\mathrm{x}}$ will be more than offset by the reduction in mixing-zone $\mathrm{NO}_{\curlyvee}$.

Rich Zone NO. The NO formation in the rich section depends on a complex reaction kinetic mechanism, the flow pattern, and the time available. In general it has a faster time scale than in lean mixtures. Conventional RQL combustors with direct fuel injection normally provide a long residence time for homogenization and equilibration of the rich mixture before injection of bypass air. This ensures that the mixture is uniformly at rich low- $\mathrm{NO}_{x}$ conditions. In contrast, RWQL designs with external or internal rich combustion should be designed to minimize the residence time of the rich mixture at combustion temperature, provided heat release is substantially realized.

The residence time in the rich combustor can be very short because it is not required to equilibrate and mix thoroughly before expansion. Indeed, continuation of mixing and reaction of some residual fuel during and after expansion in the wave rotor will be beneficial, since this will provide radicals that can reduce $\mathrm{NO}$ as the temperature falls. Sufficient time can be provided downstream for homogenization (aided by wave-rotor-induced flow shear) and approach to low- $\mathrm{NO}_{x}$ equilibrium at lower temperature before injecting bypass air.

Mixing Zone NO. Mixing zone NO formation is governed primarily by the peak temperature (near-stoichiometric mixture) and the residence time at high temperatures. The residence time depends on the rate and completeness of mixing.

The main design variables determined from the overall cycle design are: (a) available pressure differential between the rich product gas and the bypass air; (b) bypass to mainstream mass flow ratio; (c) the temperature of each stream; and (d) the equivalence ratio of the rich zone.

Dilution zone mixing studies (Holdeman, 1991) have identified two significant design parameters that influence the mixing pattern: jet-to-mainstream momentum flux ratio $(J)$ and orifice spacing-to-duct height ratio $(S / H)$. It has been shown that the mixing can be considerably enhanced by increasing the pressure differential (and thus $J$ ).

For the example design presented previously the peak stoichiometric temperature is $3660 \mathrm{R}(2030 \mathrm{~K})$, and the peak NO formation rate is only 0.004 per ms. By contrast, for a conventional cycle with RQL combustion and equivalent performance, the corresponding peak NO formation rate is about 1 per $\mathrm{ms}$. The increased mixing rate will also help. Therefore, the contribution to NO formation in the mixing zone of the wave rotor engine cycle can be expected to be minimal.

\section{Conclusions}

Design and simulations performed indicate a substantial benefit in performance enhancement and emissions reduction by using the RWQL concept. It provides the benefits of wave rotor enhancement of gas turbine engines, while controlling NOx emissions. Rich-Wave-Quench-Lean (RWQL) cycles have been developed and examined parametrically. CFD simulations have been performed on the unsteady wave rotor flows and periodic solutions have been obtained for cycles matched to an external combustion scheme. Preliminary reactive-flow CFD simulations have also been performed on the combustion stage of internal-combustion wave rotor cycles. The bypass turbine scheme is considerably more effective than the splitter scheme because of the large work transfer from the rich product gas to the air. Although this introduces greater complexity, especially with external combustion, the payoff is substantial, with the stoichiometric temperature in the mixing zone being reduced by $450 \mathrm{R}(250 \mathrm{~K})$, and engine performance improved equivalent to a nearly $400 \mathrm{R}(220 \mathrm{~K})$ rise in TIT. Equivalent benefits could be obtained if the wave rotor produces shaft work instead of the bypass turbine. Alternately, the bypass turbine's output and the overall performance and temperature reductions could be enhanced by augmenting heat transfer from the rich gas to the bypass air. The mechanical complexity could be simplified, and additional benefits obtained, if internal combustion is accomplished. In particular, the rich zone $\mathrm{NO}_{x}$ formation could be reduced, losses reduced, and pressure gain increased. Issues relating to combustion rate, consistency, and hardware design remain to be addressed.

\section{Acknowledgments}

This work was supported by NASA Lewis Research Center via grants to Cornell University and SBIR contract (No. NAS327208 ) to CFD Research Corporation, monitored by Dr. ChiMing Lee. Discussions of this work with Mr. Clifford Smith were very helpful.

\section{References}

Azoury, P.H., 1965-1966, “An Introduction to the Dynamic Pressure Exchanger." Proc. IMechE, Vol. 180, Part 1.

Foa, J.V.. 1960, Elements of Flight Propulsion. Wiley. New York.

Holdeman, J.D., 1993, “Mixing of Multiple Jets With a Confined Subsonic Crossflow," Progress in Energy and Combustion Sciences, Vol. 19, pp. 31-70.

Kantrowitz A., 1958, "One-Dimensional Treatment of Nonsteady Gas Dynamics," in: Fundamentals of Gas Dynamics, H.W. Emmons, ed., Princeton University Press.

Nalim, M.R., Mocsari, J.C., and Resler, E.L., Jr., 1993, “'Wave Cycle Design for $\mathrm{NO}_{x}$-Limited Wave Rotor Core Engines for High Speed Propulsion," ASME Paper No. 93-GT-426.

Nalim, M.R., 1994a, "Wave Cycle Design for Wave Rotor Engines With Limited Nitrogen Oxide Emissions," Ph.D. Thesis, Cornell University, Ithaca, NY.

Nalim, M.R., 1994b, "Advanced Wave Rotor Design for Low NO, Turbine Engines," NASA SBIR Phase 1 Contract No. NAS3-27208 Final Report, Proj. 4355, CFD Research Corp.. Huntsville, AL.

Resler, E.L, Jr., Mocsari, J.C., and Nalim, M.R., 1994, "Analytic Design Methods for Wave Rotor Cycles," Journal of Propulsion and Power, Vol. 10, No. 5 , pp. $683-689$.

Shreeve, R.P. and Mathur, A., eds., 1985, Proc.1985 ONR/NAVAIR Wave Rotor Research and Technology Workshop. Naval Postgrauuate School, Monterey. CA.

Sladky, J.F.. Jr., ed.. 1984, "Machinery for Direct Fluid-Fluid Energy Exchange," Vol. AD-07. Aerospace Div., ASME

Wilson. J., and Fronek. D.. 1993. "Initial Results From the NASA-Lewis Wave Rotor Experiment," Paper No. AIAA-93-2521. 